\title{
ANTHROPOMETRIC STUDY OF EXTERNAL EAR IN NORTH INDIAN
} POPULATION

\section{Rashi Nigam ${ }^{* 1}$, Kiran Kumar P ${ }^{2}$, Saurabh Kulshreshtha ${ }^{3}$.}

*1,2 Assistant Professor, Department of Anatomy, Rama Medical College Hospital \& Research Centre, Kanpur, Uttar Pradesh, India.

${ }^{3}$ Professor, Department of Anaesthesiology, Rama Medical College Hospital \& Research Centre, Kanpur, Uttar Pradesh, India.

\section{ABSTRACT}

Introduction: Anthropometry is a series of systematize measuring techniques that express quantitatively the dimensions of human body and skeleton which shows variation according to age, gender and race. The identification of an individual by age and sex possesses difficulty in revealing its identify. Various parameters have been used to establish the identification of individuals. Anthropometry of external features of the pinna is one of them.

Objective: The aim of study to differentiate the morphometric features of external ear among males and females and also between the right and left ear in each gender.

Materials and Methods: The study was conducted on 100 students which consist of 62 males and 58 female MBBS students with the age between 18-25 years in Rama Medical College, Hospital \& Research Centre, Kanpur. Following anthropometric parameters used were: Height of ear (HE), Width of ear (WE), lobular height (LH), Lobular width (LW), Auricular index (AI) and Lobular index (LI).

Results: In the present study, that all the parameters of right ear slightly greater than left ear among male population except LW and LI. All the parameters of left ear slightly greater than right ear among female population except $\mathrm{HE}$ and WE. The mean of $\mathrm{HE}, \mathrm{WE}$ and $\mathrm{Al}$ of right ear slightly greater than left ear among combined (male + female) population whereas $\mathrm{LH}, \mathrm{LW}$ and $\mathrm{LI}$ which were slightly lesser on right side than left side. All the parameters of external ear greater in males than female except LH on both sides which were greater in females than males.

Conclusion: This anthropometric study is useful in the plastic reconstructive surgeries to correct the deformities and also useful in making the hearing aids or prosthesis, ear phones and head phones.

KEY WORDS: Anthropometry, external ear, hearing aids.

Address for Correspondence: Dr. Rashi Nigam, Rama Medical College Hospital \& Research Centre, Kanpur, Uttar Pradesh 209217, India. E-Mail: drrashinigam@gmail.com

Access this Article online

Quick Response code

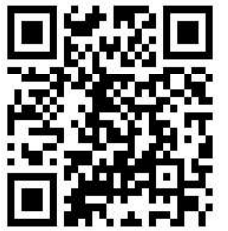

DOI: $10.16965 /$ ijar.2019.228

Journal Information

International Journal of Anatomy and Research

ICV for 2016 ISSN (E) 2321-4287 | ISSN (P) 2321-8967

90.30

https://www.ijmhr.org/ijar.htm

DOI-Prefix: https://dx.doi.org/10.16965/ijar

Article Information

Received: 08 May 2019

Peer Review: 11 May 2019

Revised: None
Accepted: 08 Jul 2019

Published (O): 05 Aug 2019

Published (P): 05 Aug 2019

\section{INTRODUCTION}

Anthropometry is a series of systematize measuring techniques that express quantitatively the dimensions of human body and skeleton which shows variation according to age, gender and race $[1,2]$. The identification of an individual by age and sex possesses difficulty in revealing its identify. Various parameters have been used to establish the identification of individuals. Anthropometry of external features of the pinna is one of them [3]. The human ear is divided into external, middle and internal ear. The pinna and the external acoustic meatus form the external ear. The lateral surface of the pinna 
is irregularly concave faces slightly forward and displays numerous eminences and depressions. These structure do not merely act as trumpet; they are the first of series of stimulus modifies in the auditory apparatus (William et al., 1987) [4].

The existence of abnormality of the external ear as an early diagnostic feature for existence of an abnormality of the urinary tract, due to concomitant development of the external ear and urinary tract during embryogenesis has been documented [5]. Kenny (1989) suggested and interesting association between the diagonal ear lobule crease and myocardial infarction risk [6]. Moreover, ear prints have been used in forensic investigations since the mid-1960s [7]. The aim of study to differentiate the morphometric features of external ear among males and females and also between the right and left ear in each gender.

\section{MATERIALS AND METHODS}

The study was conducted on 100 students which consist of 62 males and 58 female MBBS students with the age between $18-25$ years in Rama Medical College, Hospital \& Research Centre, Kanpur, Uttar Pradesh, India. Participants with congenital ear anomalies and ear surgeries were excluded from the study. All measurements were taken with their consent. Materials used for the study were vernier caliper. Following anthropometric parameters used were: Height of ear (HE), Width of ear (WE), lobular height (LH), Lobular width (LW), Auricular index (Al) and Lobular index (LI).

The HE was measured as distance from the most inferior projection of the ear lobule to the most superior projection of the helix. The WE was measured as most anterior and posterior points of the ear. The LH was taken as the distance from the most inferior end of the lobule to the base of the tragal notch. The LW was measured as the horizontal width of lobule at the midpoint of lobular height. Al was calculated as Width of ear/Height of ear $\times 100$. LI was measured as Lobular width/Lobular height $\times 100$.

In our study, measurements were taken twice on each subject and calculated the arithmetical mean of the two measurements for precision.

Statistical analysis: The numerical data were analyzed by using the SPSS software 21 version. Independent samples t-test were performed to compare the data according to the gender. Comparisons of measurements taken from the left and right ears of given sex was performed using paired samples t-test.

Fig. 1: Measuring method of external ear with vernier caliper.

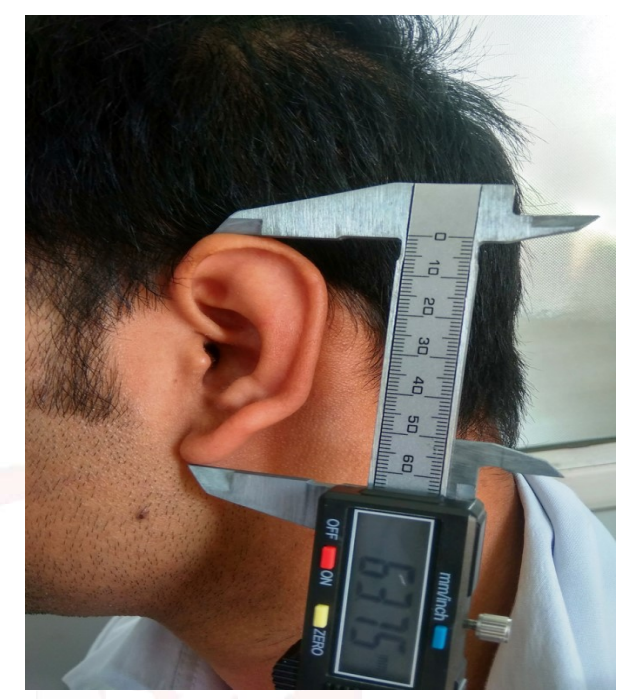

\section{RESULTS}

In the present study, Table 1 revealed that all the parameters of right ear slightly greater than left ear among male population except lobular width (LW) and lobular index (LI) which were slightly lesser on right side than left side. But, all these were statistically insignificant except lobular height $(p=0.034)$. All the parameters of left ear slightly greater than right ear among female population except height of ear and width of ear which were slightly greater on right side than left side. But, all these were statistically insignificant. The mean values of height of ear (HE), width of ear (WE) and auricular index (Al) of right ear slightly greater than left ear among combined (male + female) population whereas lobular height (LH), Lobular width (LW) and Lobular index (LI) which were slightly lesser on right side than left side. But, all these results were statistically insignificant.

According toTable.2; all the parameters of external ear greater in males than female except lobular height on both sides which were greater in females than males. All the parameters were showing statistically significant difference except lobular width (LW), auricular index (AI) on both side and lobular index (LI) on left side also which were statistically insignificant. 
Table 1: Different parameters of right and left external ear among study population.

\begin{tabular}{|c|c|c|c|c|c|c|c|}
\hline Parameters & Side of ear & $\begin{array}{c}\text { Mean } \pm \text { SD }(\mathrm{cm}) \\
(\mathrm{n}=62)\end{array}$ & p-value & $\begin{array}{c}\text { Mean } \pm \text { SD }(\mathrm{cm}) \\
(\mathrm{n}=58)\end{array}$ & p-value & $\begin{array}{c}\text { Mean } \pm S D(\mathrm{~cm}) \\
(\mathrm{n}=120)\end{array}$ & p-value \\
\hline \multirow{2}{*}{ Height of ear (HE) } & Right & $6.24 \pm 0.84$ & \multirow{2}{*}{0.606} & $5.93 \pm 0.52$ & \multirow{2}{*}{0.664} & $6.10 \pm 0.74$ & \multirow{2}{*}{0.498} \\
\hline & Left & $6.22 \pm 0.69$ & & $5.91 \pm 0.44$ & & $6.01 \pm 0.75$ & \\
\hline \multirow{2}{*}{ Width of ear (WE) } & Right & $3.38 \pm 0.33$ & \multirow{2}{*}{0.749} & $3.14 \pm 0.47$ & \multirow{2}{*}{0.976} & $3.27 \pm 0.42$ & \multirow{2}{*}{0.789} \\
\hline & Left & $3.35 \pm 0.68$ & & $3.14 \pm 0.36$ & & $3.25 \pm 0.55$ & \\
\hline \multirow{2}{*}{ Lobular Height (LH) } & Right & $1.90 \pm 0.30$ & \multirow{2}{*}{$0.034^{*}$} & $2.02 \pm 0.30$ & \multirow{2}{*}{0.419} & $1.95 \pm 0.30$ & \multirow{2}{*}{0.977} \\
\hline & Left & $1.83 \pm 0.31$ & & $2.10 \pm 0.63$ & & $1.96 \pm 0.51$ & \\
\hline \multirow{2}{*}{ Lobular width (LW) } & Right & $1.96 \pm 0.31$ & \multirow{2}{*}{0.49} & $1.89 \pm 0.35$ & \multirow{2}{*}{0.208} & $1.93 \pm 0.33$ & \multirow{2}{*}{0.168} \\
\hline & Left & $2.01 \pm 0.66$ & & $2.00 \pm 0.54$ & & $2.00 \pm 0.60$ & \\
\hline \multirow{2}{*}{ Auricular Index (AI) } & Right & $5.50 \pm 0.79$ & \multirow{2}{*}{0.731} & $5.31 \pm 0.74$ & \multirow{2}{*}{0.853} & $5.41 \pm 0.77$ & \multirow{2}{*}{0.855} \\
\hline & Left & $5.44 \pm 1.28$ & & $5.33 \pm 0.63$ & & $5.39 \pm 1.02$ & \\
\hline \multirow{2}{*}{ Lobular Index (LI) } & Right & $10.46 \pm 1.83$ & \multirow{2}{*}{0.167} & $9.52 \pm 1.63$ & \multirow{2}{*}{0.267} & $10.00 \pm 1.80$ & \multirow{2}{*}{0.075} \\
\hline & Left & $11.18 \pm 3.95$ & & $10.01 \pm 3.02$ & & $10.61 \pm 3.57$ & \\
\hline
\end{tabular}

SD: Standard Deviation; * significant

Table 2: comparison of different parameters of external ear in males and females study population.

\begin{tabular}{|c|c|c|c|c|c|c|}
\hline \multirow[b]{2}{*}{ Parameters } & \multicolumn{2}{|c|}{ Right } & \multirow[b]{2}{*}{ p-value } & \multicolumn{2}{|c|}{ Left } & \multirow[b]{2}{*}{$p$-value } \\
\hline & $\begin{array}{c}\text { Male }(n=62) \\
\text { Mean } \pm S D(\mathrm{~cm})\end{array}$ & $\begin{array}{l}\text { Female }(n=58) \\
\text { Mean } \pm S D \quad(\mathrm{~cm})\end{array}$ & & $\begin{array}{c}\text { Male }(\mathrm{n}=62) \\
\text { Mean } \pm \text { SD }(\mathrm{cm})\end{array}$ & $\begin{array}{l}\text { Female }(n=58) \\
\text { Mean } \pm S D \quad(\mathrm{~cm})\end{array}$ & \\
\hline Height of ear (HE) & $6.25 \pm 0.88$ & $5.93 \pm 0.52$ & $0.023^{*}$ & $6.22 \pm 0.69$ & $5.91 \pm 0.44$ & $0.006 *$ \\
\hline Width of ear (WE) & $3.38 \pm 0.33$ & $3.14 \pm 0.47$ & $0.002^{*}$ & $3.35 \pm 0.68$ & $3.14 \pm 0.36$ & $0.036^{*}$ \\
\hline Lobular Height (LH) & $1.90 \pm 0.30$ & $2.02 \pm 0.30$ & $0.034^{*}$ & $1.83 \pm 0.31$ & $2.09 \pm 0.64$ & $0.004 *$ \\
\hline Lobular width (LW) & $1.96 \pm 0.31$ & $1.89 \pm 0.35$ & 0.3 & $2.02 \pm 0.65$ & $2.00 \pm 0.54$ & 0.889 \\
\hline Auricular Index (Al) & $5.50 \pm 0.80$ & $5.31 \pm 0.74$ & 0.171 & $5.44 \pm 1.28$ & $5.33 \pm 0.63$ & 0.549 \\
\hline Lobular Index (니) & $10.46 \pm 1.84$ & $9.52 \pm 1.63$ & $0.004 *$ & $11.18 \pm 3.95$ & $10.01 \pm 3.02$ & 0.072 \\
\hline
\end{tabular}

SD: Standard Deviation; * significant

\section{DISCUSSION}

The mature height of ear reaches at 13 years in males and 12 years in females [8]. In this study, all the parameters of external ear were slightly greater on right side than left side among both sexes which were statistically insignificant. Shireen S and Karadkhelkar VP also found the similar results in both sexes whereas their results were statistically significant [9]. M.G. Taura et al., also found that all parameters were higher on right side than left side except height of ear which was same on both sides [10]. But, D. Deopa et al., also found that all parameters were more on left side than right side whereas it was not statistically significant [11]. Sharma $\mathrm{N}$ was also compared the anthropometry of external ear between left and right side were showing the insignificant difference [2].

In our study, all the parameters of external ear greater in males than female except lobular height on both sides which were greater in females than males. All the parameters were showing statistically significant difference except lobular width (LW), auricular index (AI) on both side and lobular index (LI) on left side also which were statistically insignificant.

U. Ekanem et al., [12] and Taura M.G. et al., [10] found that all parameters were greater in males than females in Nigerians. D. Deopa [11] also noticed that all the measurements were higher in males than females on both sides. They also observed that Total height of ear and ear width were found to be significantly greater among male and the left ear indices were found to be higher than the right ones for all the subjects. But, in female subjects, the right indices were found to be greater than the left ones. There was no significant difference found in the ear index between males and females and the right lobular indices were found to be higher than the left ones for all the subjects. 
Senthil Kumar B studied among Malaysian and Indian population. Malaysian male total ear length, width and length of cartilaginous ear showed higher values when compared to female whereas the lobular height were longer in female among Indians than that of Malaysian males. The Indian males total ear length, width, length of cartilaginous ear and lobular length were higher than that of Indian females [13]. Ebho [14], and Sharma N [2] noticed that ear dimensions were higher in males whereas lobular width and height were larger in females.

Sangeeta S and Anisha B [15] studied the height and width of ear lobule more in right side than left side which was statistically significant and lobular width was more in male than female which was also statistically significant whereas there was no statistical significance of lobular height among males and females. Wang et al., observed that lobule dimensions are not significantly difference in two genders [16].

In the present study, we were also observed that lobular height is greater among females than males which may be due to wearing of jewellery by female on ear lobule.

\section{CONCLUSION}

This anthropometric study is useful in identification of congenital deformities, acquired deformities due to traumatic injuries. So, these measurements will be implicated in the plastic reconstructive surgeries to correct the deformities and also useful in making the hearing aids or prosthesis, ear phones and head phones.

\section{Conflicts of Interests: None}

\section{REFERENCES}

[1]. Shastry CKR and Bhat BPR. Anthropometric measurements of newborns. Int J Contemp Pediatr. 2015;2(2):85-89.

[2]. Sharma N. Anthropology measurement and cross sectional surveying of ear pinna characteristics in Northern India. J Exp Clin Anat 2016;15:102-6.
[3]. Brucker M. J., Patel J., Sullivan P.K. A morphometric study of the external ear: Age and sex related differernces. Plast Reconstr Surg. 2013;112(2):64752.

[4]. Williams, P L., L.H. Bannister, M.M. Berry, P. Collins, M. Dyson, J. E. Dusseck and M.W.J. Ferguson, 1987. Grays's Anatomy. 37 th Edn, Churchill Livingstone, New York, London, Madrid, ISBN:0443071683, pp: 1367-1370.

[5]. Perrin, P., H. Baithelme, D. Moyot, C.Pem and M.Schmitt. External ear and abnormality of the urinary tract: A Comparative study of 2 series (100 and 150 cases). Rev. Laryngol. Otol. Rhinol. (BOrd)., 1999;112:399-403.

[6]. Kenny Meijerman L, Thean A and Maat G. Earprints in forensic Investigations. Forensic Sci. Med. Pathol. 2005;1:4:247.

[7]. Ito I, Imada. M, Ikeda M, et al. A stud y of age changes in adult human auricular cartilage with special emphasis on elastic fibers. Laryngoscope 2001;111:881-6.

[8]. Shireen S, Vrushail P. Karadkhelar. Anthropometric measurements of human external ear. J OF Evolution of Med and Dent Sci . 2015:4(59).

[9]. Taura M.G., Adamu L.H.and Modibbo M.H. External ear anthropometry among Hausas of Nigeria; the search of sexual dimorphism and correlations. World Journal of Medicine and Medical Science Research. 2013;1(5);091-095.

[10].D. Deopa, H.K Thakkar, Chandra Prakash, R. Niranjan, M.P Barua Anthropometric measurement of external ear of medical student in Uttarkhand Region journal of the Anatomical society of India 2013;62:79-83.

[11]. A.U. Ekanneum S.H. Garda ,T.S. Musa and N.D. dare Anthropometric Study of the Pinna (Auricle) among Adult Nigerians Resident in Maiduguri Metropolis J. Med. Sci 2010;10(6):176-180.

[12]. Senthil Kumar B, Panneer Selvi G. Morphometry of ear pinna in sex determination. Int J Anat Res 2016;4(2):2480-84.

[13]. Eboh D. Morphological changes of the human pinna in relation to age and gendr of Urhobo people in Southern Nigeria. J Exp Clin Anat 2013;12:68-74.

[14]. Sangeetha.S and Anisha.B Anthropometric measurements of human ear lobule in adult student population. Int J Anat Res 2017;5(2.2):3748-87.

[15]. Wang B., Dong Y., Zhao Y., Shizhu B.S., Wu G. Computed tomography measurement of the auricle in Han population of North China. J Plast Reconstr Aesthet Surg 2011;64(1):34-40.

How to cite this article:

Rashi Nigam, Kiran Kumar P, Saurabh Kulshreshtha. ANTHROPOMETRIC STUDY OF EXTERNAL EAR IN NORTH INDIAN POPULATION. Int J Anat Res 2019;7(3.2):6800-6803. DOI: 10.16965/ijar.2019.228 